\title{
Why don't more girls choose to pursue a science career?
}

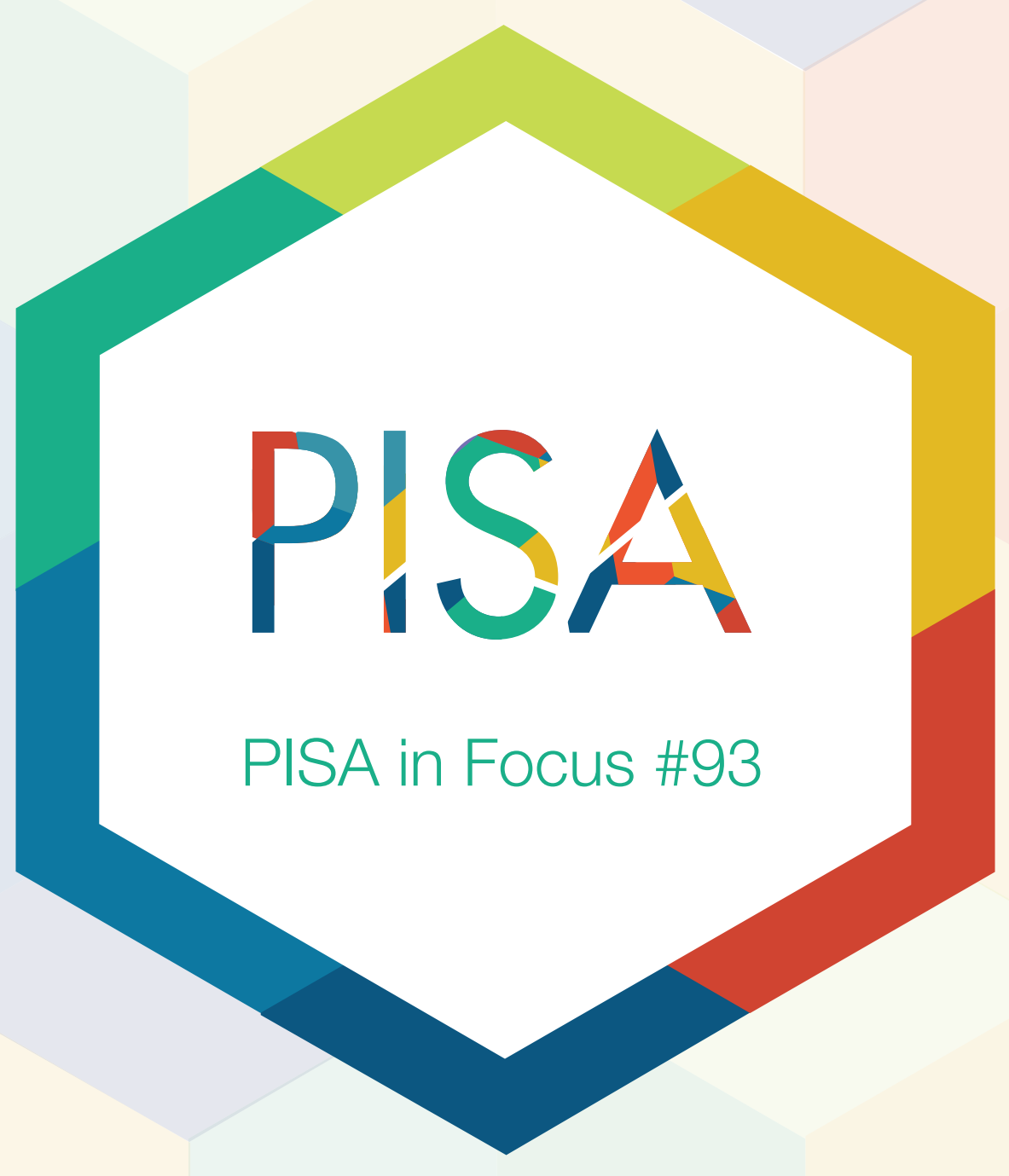




\section{Why don't more girls choose to pursue a science career?}

- Boys outperform girls in science in 22 PISA-participating countries, and girls outperform boys in 19. However, boys have a relative strength in science in 65 out of the 67 participating countries, meaning that they score higher in science than their average performance across all three main PISA subjects.

- Boys show greater confidence when learning science (in 39 countries) and greater interest in broad science topics (in 51 countries) than girls do.

- The differences in favour of boys in relative academic strength, in confidence and interest in science are associated with lower graduation rates among women in STEM fields.

When new PISA data are published, many researchers around the world analyse them with the aim of shedding light on all sorts of questions. One question in search of an answer: why are women under-represented in science, technology, engineering and mathematics (STEM) professions? Using data from the Program for International Student Assessment (PISA), Gijsbert Stoet and David Geary examined the nature of the gender gap in STEM fields. The authors analysed data from 67 countries and economies participating in the 2015 cycle of PISA; these data were supplemented by country-level indicators on gender equality (the Global Gender Equality Index) and the proportion of women graduating in a STEM field. Their analysis yielded an interesting result.

\section{The gender gap in STEM studies is already evident among 15-year-olds.}

Across the 67 countries and economies that participated in PISA 2015, girls outperformed boys in science in 19, while boys outperformed girls in 22. In all other countries, the gender differences were not statistically significant. When the authors analysed gender gaps by looking at each student's "relative performance" or "strength" across the three subjects (box), the authors found that girls were stronger in reading in all countries, while boys were stronger in mathematics in all countries, and in science in 65 out of 67 countries/economies. In other words, boys scored higher in science and mathematics compared to their all-subjects average while girls scored higher in reading. These differences could explain why boys are more likely than girls to choose careers in STEM fields, even though the overall performance of girls and boys is similar: students may choose their field of study based on their comparative strengths, rather than on their absolute strengths. Girls may be as good as boys in science, but are, on average, likely to be even better in reading.

\section{The authors rely on three indicators in their analysis}

The Global Gender Equality Index (2015 data) assesses the degree to which girls and women fall behind boys and men on 14 indicators (e.g. earnings, tertiary enrolment ratio, life expectancy, seats in parliament). Higher values on this index indicate greater equality between men and women.

Women among STEM graduates (data for 2012 to 2015 period) measures the proportion of women who successfully completed a university degree in a STEM field among all STEM graduates.

Relative performance or academic strength in PISA 2015 measures the performance of a student in one subject (mathematics, science or reading) relative to the student's average performance in all three subjects. Students strong in science will have a positive relative performance in this subject (i.e. science performance is above the average performance in the three subjects). All performance scores were first standardised within each country, meaning that they are expressed in units corresponding to the overall variation (standard deviation) observed in each country. 
Gender equality and gender differences in relative strength in science, and the percentage of women among STEM graduates

a)

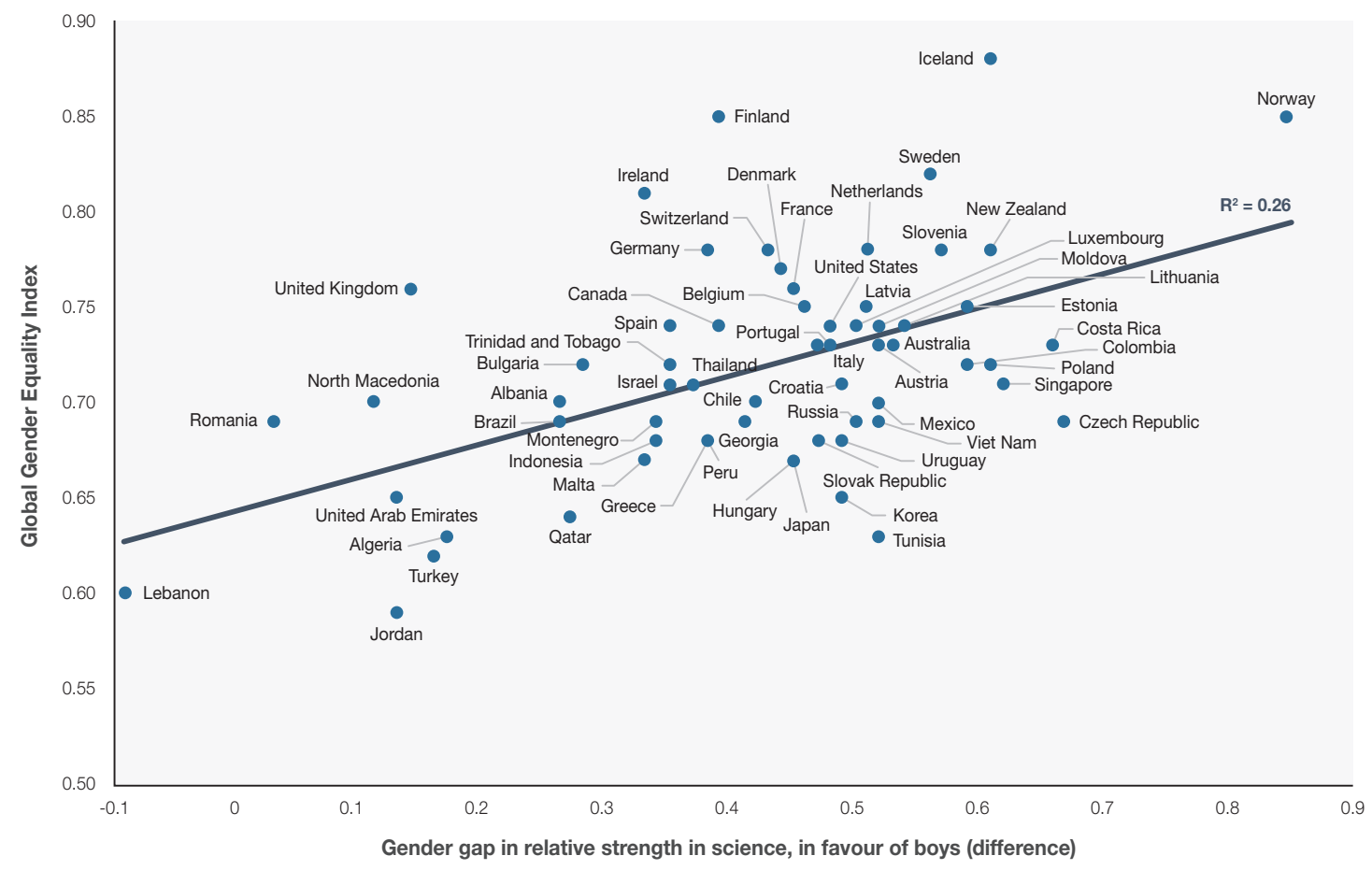

b)

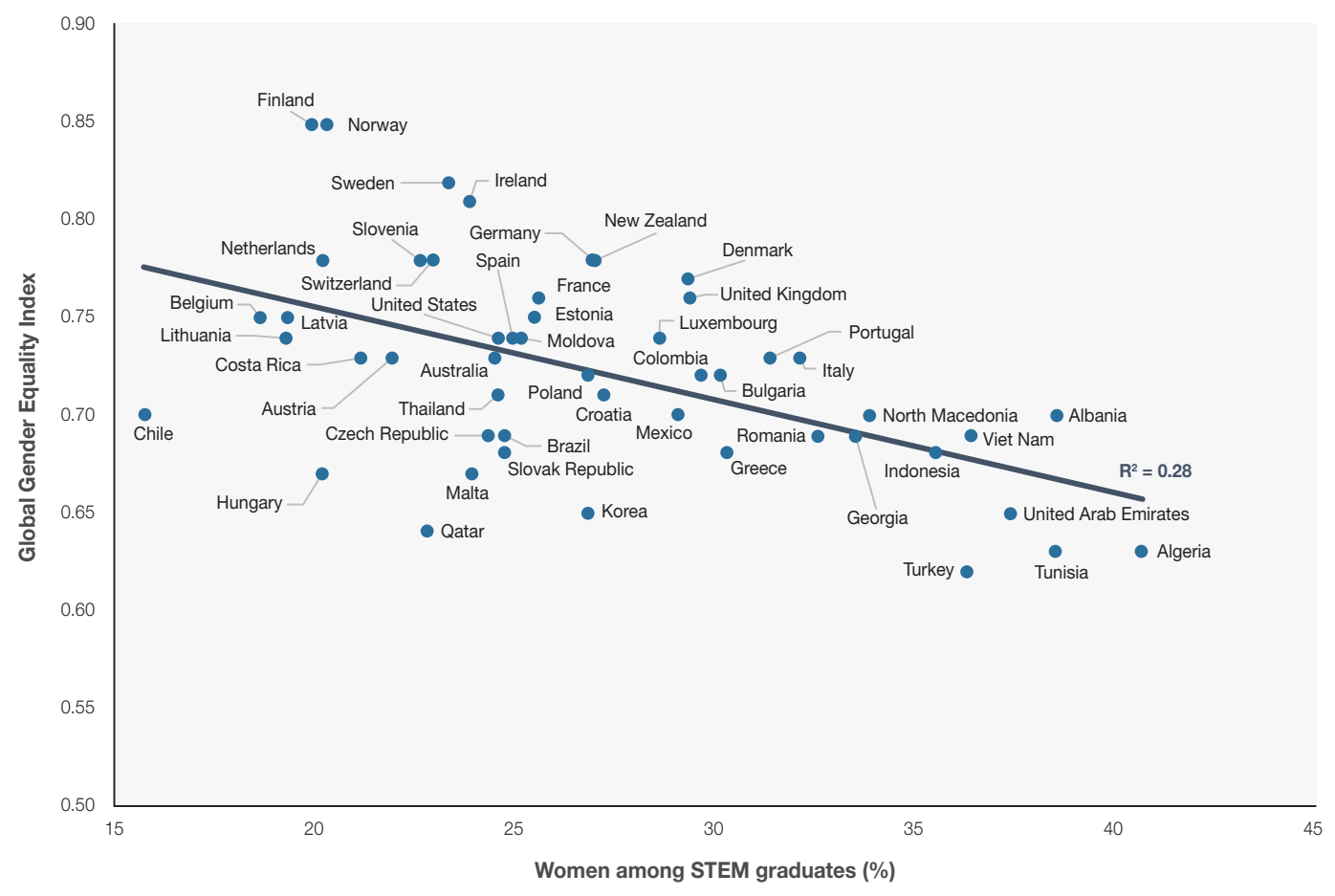

Source: G. and D.C. Geary (2018), "The Gender-Equality Paradox in Science, Technology, Engineering, and Mathematics Education”, Psychological Science, 29/4, 581-593, https://doi.org/10.1177/0956797617741719 
Interestingly, in countries with more gender equality, like Sweden and Norway (i.e. those with higher values on the Global Gender Equality Index), the gender gaps in relative science performance in favour of boys is larger, and fewer women graduate with a universitylevel STEM degree than in countries with less gender equality.

\section{Boys are more confident and interested in broad science topics.}

PISA also shows that, in 2015, boys' science self-efficacy was higher than that of girls in 39 out of the 67 participating countries and economies. Similarly, in 51 countries/economies, boys expressed a stronger interest in broad science topics than girls did. Again, the study shows that these gender gaps in self-efficacy and interest were particularly strong in countries with greater gender equality.

These differences between boys and girls in relative academic strength, self-efficacy, enjoyment of and interest in science account for a large proportion of the deficit in women's STEM graduation rates.

\section{Gender difference in science self-efficacy and the Global Gender Gap Index}

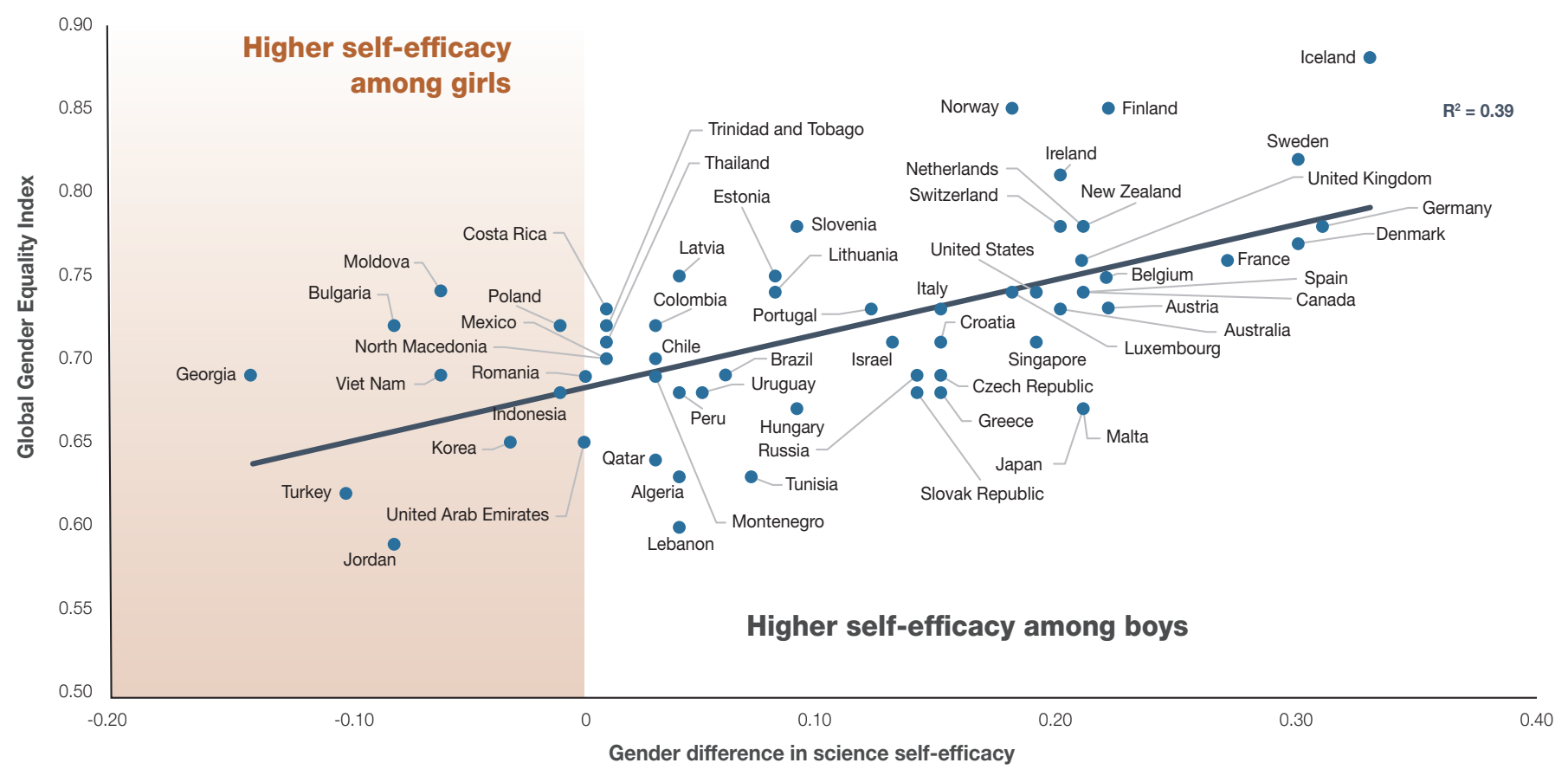

Source: G. and D.C. Geary (2018), “The Gender-Equality Paradox in Science, Technology, Engineering, and Mathematics Education”, Psychological Science, 29/4, 581-593, https://doi.org/10.1177/0956797617741719

\section{Based on PISA data, more women are expected to pursue careers in STEM fields than actually do.}

The authors used different science proficiency and attitudinal criteria, based on PISA 2015 data, to calculate the share of girls among all students who could be expected to complete a university STEM degree. The results show that there are far more girls among students attaining PISA proficiency Level 4 in all three domains (49\%, on average across the 67 participating countries and economies) than women who graduated with a university STEM degree between 2012 and 2015 (28\%, on average). Moreover, when the authors further restricted the pool of students who might complete a STEM university degree to high performers whose enjoyment of science, interest in science, and science self-efficacy fell in the top half of the international distribution of those attitudes, $41 \%$ of that pool were girls. 
The difference between expected and actual proportions of women among STEM graduates shrank significantly when the authors further restricted their definition of students expected to be successful in a STEM university programme to those with a relative strength in science and mathematics, rather than in reading. Using this definition, only one in three girls (34\%) was expected to successfully complete a STEM degree. However, in most countries the percentage of women graduating in a STEM field was still smaller than expected.

\section{5-year-old girls who could successfully complete a STEM university degree and women graduating with a STEM university degree}

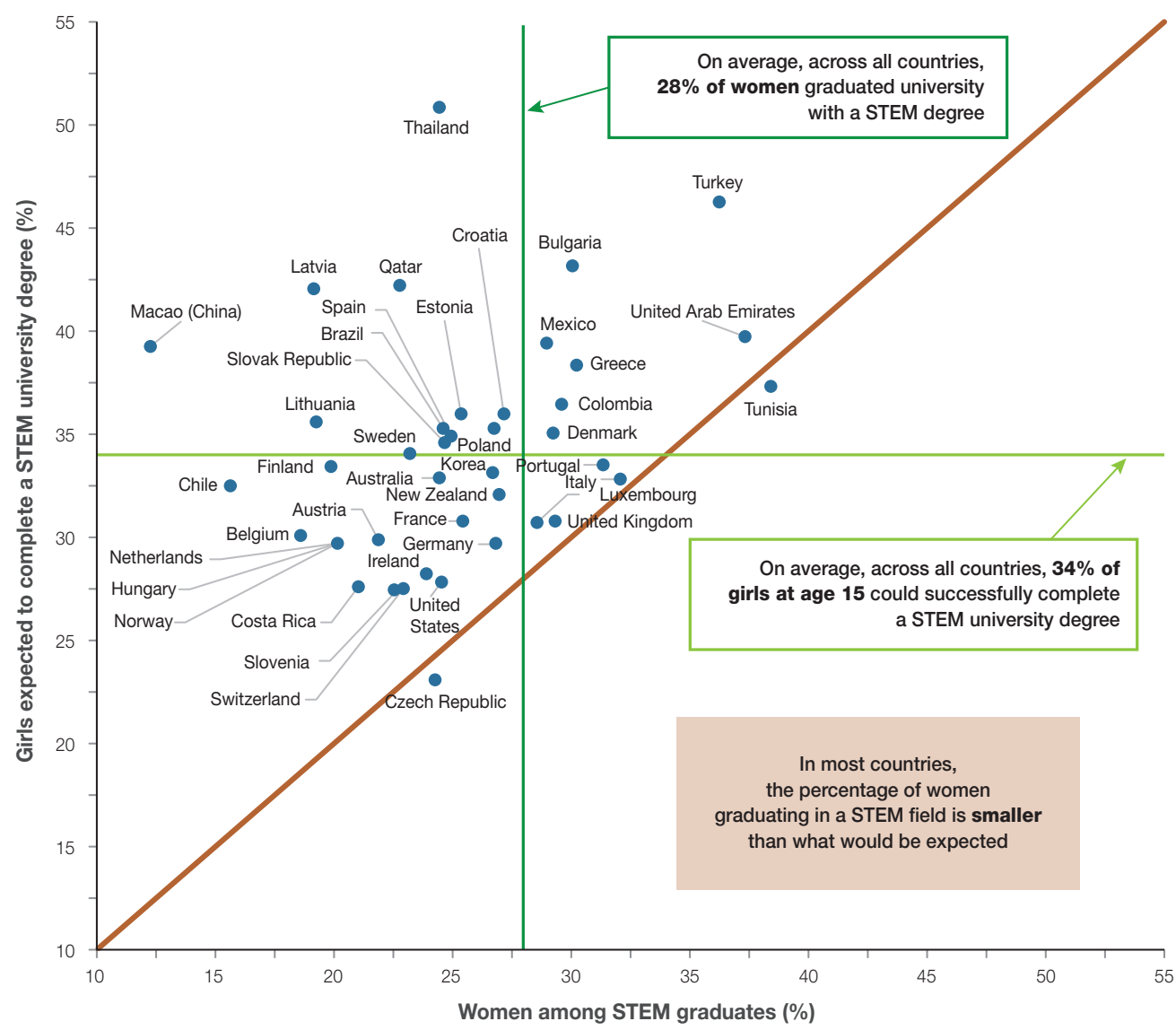

Note: Girls who are expected to complete a university-level STEM degree are those who perform at PISA proficiency Level 4 in science and who are in the top half of the international distribution of enjoyment, interest and self-efficacy in science.

Source: G. and D.C. Geary (2018), “The Gender-Equality Paradox in Science, Technology, Engineering, and Mathematics Education”, Psychological Science, 29/4, 581-593, https://doi.org/10.1177/0956797617741719

\section{The bottom line}

The study by Stoet and Geary (2018) suggests that students may be influenced in their career choices by their understanding of their relative academic strengths as well as their confidence and interest in science. Unlike many highperforming boys, many high-performing girls may not pursue a career in science, even if they are capable of succeeding in it, because they are likely to be top of the class in non-science subjects too. This means that tackling boys' underperformance in reading may be just as important to ensure greater representation of women in science careers as supporting girls' performance in and attitudes towards STEM subjects. 
Contact: Tarek Mostafa (tarek.mostafa@oecd.org)

See: Stoet, G. and D.C. Geary (2018), "The Gender-Equality Paradox in Science, Technology, Engineering, and Mathematics Education", Psychological Science, 29/4, 581-593, https://doi.org/10.1177/0956797617741719

Coming next month: Does living in a city make a difference in how and what you learn?

This paper is published under the responsibility of the Secretary-General of the OECD. The opinions expressed and the arguments employed herein do not necessarily reflect the official views of OECD member countries.

This document, as well as any data and map included herein, are without prejudice to the status of or sovereignty over any territory, to the delimitation of international frontiers and boundaries and to the name of any territory, city or area.

The statistical data for Israel are supplied by and under the responsibility of the relevant Israeli authorities. The use of such data by the OECD is without prejudice to the status of the Golan Heights, East Jerusalem and Israeli settlements in the West Bank under the terms of international law.

This work is available under the Creative Commons Attribution-NonCommercial-ShareAlike 3.0 IGO (CC BY-NC-SA 3.0 IGO). For specific information regarding the scope and terms of the licence as well as possible commercial use of this work or the use of PISA data please consult Terms and Conditions on www.oecd.org. 